(C) 2007 IEEE. Personal use of this material is permitted. Permission from IEEE must be obtained for all other uses, in any current or future media, including reprinting/republishing this material for advertising or promotional purposes, creating new collective works, for resale or redistribution to servers or lists, or reuse of any copyrighted component of this work in other works. 


\title{
Theory and Operation Principle of a HTS High Q Resonant Circuit
}

\author{
Jian X. Jin, Chang M. Zhang, You G. Guo, and Jian G. Zhu, Senior Members, IEEE
}

\begin{abstract}
High-temperature superconductor (HTS) technology has been used to develop an advanced high $Q$ resonant power electronic circuit and its special device. With HTS techniques, a very high $Q$ circuit can be achieved; consequently special aspects such as high voltage generation and current control can be practically realized. Theoretical study has been carried out with regard to this HTS high Q resonant method, as well as a prototype device has been made for experimental verification of the voltage generation and current control, as details described in this paper.
\end{abstract}

Index Terms-High-temperature superconductors, Bi-2223/Ag wires, Resonance, Inductors, High-voltage techniques.

\section{INTRODUCTION}

$\mathrm{H}$ IGH-temperature superconductor (HTS) technology has been used to develop an advanced high Q resonant power electronic circuit and its devices. A high Q R-C-L series resonant circuit has been built and analyzed. With HTS techniques, a very high $\mathrm{Q}$ circuit can be achieved; consequently special aspects such as high voltage generation and high current control can be practically realized. High voltage generation i.e. can be achieved by using an inductor having a high quality factor $\mathrm{Q}$ in a resonate circuit. Normal conductor technology limits the $\mathrm{Q}$ values which can be obtained. However, HTS brings a solution to build the high $\mathrm{Q}$ inductor, and this voltage generation method becomes viable for very high voltage generation. Theoretical analysis has been conducted with regard to this voltage generation and high current control method, and experimentation has also been carried out for verification.

An electronic resonant circuit with a power electronic-controlled switch has been explored with regard to its special aspects of using a HTS. The circuit special aspects have been studied, such as to form a method of very high

Manuscript received August 24, 2006.

Jian Xun Jin is with the Center of Applied Superconductivity and Electrical Engineering, University of Electronic Science and Technology of China, ChengDu, SiChuan, 610054 China (phone: 86-028-83206325; fax: 86-02883206325; e-mail: jxjin@uestc.edu.cn).

Chang Ming Zhang is with the University of Electronic Science and Technology of China, ChengDu, SiChuan, 610054 China (e-mail: zhangchm (a)126.com).

You Guang Guo is with the Faculty of Engineering, University of Technology, Sydney, NSW 2007, Australia (e-mail: youguang.guo@) eng.uts.edu.au).

Jian Guo Zhu is with the Faculty of Engineering, University of Technology, Sydney, NSW 2007, Australia (e-mail: Joe@eng.uts.edu.au). voltage generation from a low voltage source [1], [2]. This high voltage generation method using the high $\mathrm{Q}$ resonant circuit mainly consists of a HTS inductor, a DC battery source, a high voltage capacitor, and an electronic switch. An AC source is naturally used for the resonant circuit, however a DC source has been developed for convenient operation. As a basic principle for operational approach, a low voltage DC power source can be used, and its polarity is reversed at a certain frequency, which control is achieved with an electronic switch. As a fundamental principle, the resonant circuit generates the voltage which is proportional to the circuit $Q$ value. Resistance in the circuit will limit the $\mathrm{Q}$ value and therefore voltages that can be achieved in practice; however HTS technology can dramatically reduce the resistance and present a very high $\mathrm{Q}$ value in its circuit. With regard to the power electronic-controlled HTS high Q resonator, both theoretical analysis and practical operation principle will be presented in this paper with the advantages of using a high $Q$ electronic circuit which can be made with HTS Ag-clad $(\mathrm{Bi}, \mathrm{Pb})_{2} \mathrm{Sr}_{2} \mathrm{Ca}_{2} \mathrm{Cu}_{3} \mathrm{O}_{10+\mathrm{x}}$ multi-filament wires.

\section{OPERATION PRINCIPLE TheORY}

\section{A. Q Value and Feature of a Resonant Circuit}

In a R-C-L series resonant circuit, the quality factor of a resonant circuit is $\mathrm{Q}=\omega_{\mathrm{o}} \mathrm{L} / \mathrm{R}(=\mathrm{X} / \mathrm{R})$, and $\omega_{\mathrm{o}}=$ $\left[(1 / \mathrm{LC})-\left(\mathrm{R}^{2} / 4 \mathrm{~L}^{2}\right)\right]^{1 / 2}$ is the resonant frequency in $\operatorname{rad~s} \mathrm{s}^{-1}$. The potential difference across the capacitor $V_{C}$ at resonance is $Q$ times as great as the applied emf $\mathrm{V}_{\mathrm{a}}(\mathrm{rms})$ to the circuit. For a sinusoidal power supply, the voltage across the capacitor at resonance is $\mathrm{V}_{\mathrm{Cmax}}=\mathrm{Q} \mathrm{V}_{\mathrm{a}}$. For using a DC power supply with an electronic switch to reverse the polarity, the maximum voltage $\mathrm{V}_{\mathrm{Cmax}}$ can be expressed as $\mathrm{V}_{\mathrm{C} \max }=\mathrm{Q}\left(4 \mathrm{~V}_{\mathrm{B}} / \pi\right)$.

\section{B. Resistance-Less Circuit}

For the prefect superconducting R-C-L series resonant circuit, the build-up voltage for this ideal non-resistive circuit, the positive and negative peak voltages across the capacitor $\mathrm{C}$ after $n$ cycles can be described by [1]

$$
\mathrm{V}_{\mathrm{C}}(\mathrm{n})=(-1)^{\mathrm{n}+1}\left(\mathrm{~V}_{\mathrm{CO}}+2 \mathrm{n} \mathrm{V}_{\mathrm{B}}\right)
$$

where $\mathrm{n}$ is the iteration number, and $\mathrm{V}_{\mathrm{CO}}$ is the initial capacitor voltage. 


\section{Practical Resistive Circuit}

For practical resistive circuit with a DC source, when $t=\pi / \omega$, $\mathrm{i}=0$, then if the $\mathrm{V}_{\mathrm{CO}}=0$ and the DC source changes polarity at $\mathrm{t}=\mathrm{n} \pi / \omega$, the capacitor voltage. After the polarity is changed $\mathrm{n}$ times, the capacitor voltage $\mathrm{V}_{\mathrm{Cn}}$ becomes

$$
\mathrm{V}_{\mathrm{Cn}}=\left(1+\mathrm{e}^{-\mathrm{nR} \pi / 2 \mathrm{~L} \omega}\right)+2 \mathrm{~V}_{\mathrm{B}} \sum_{\mathrm{i}=1}^{\mathrm{n}-1} \mathrm{e}^{-\mathrm{i} R \pi / 2 \mathrm{~L} \omega}
$$

\section{With Step Voltage Source}

The low voltage sources can be an AC power supply, a DC battery or a rectangular pulse source. When a rectangular pulse source $u_{s}$ is used as the exciting source, the step voltage source has $u_{s}=V_{s} \varepsilon(t)$, then $V_{c}(t)=e^{-\alpha t}\left(K_{1} \cos \omega_{d} t+K_{2} \sin \omega_{d} t\right)+V_{s}$. If the circuit has zero initial state, then $\mathrm{V}_{\mathrm{c}}(0)=\mathrm{K}_{1}+\mathrm{V}_{\mathrm{s}}=0$, $\left.\frac{\mathrm{dV}_{\mathrm{c}}(\mathrm{t})}{\mathrm{dt}}\right|_{\mathrm{t}=0}=-\alpha \mathrm{K}_{1}+\omega_{\mathrm{d}} \mathrm{K}_{2}=0$; when $\mathrm{K}_{1}=-\mathrm{V}_{\mathrm{s}}, \mathrm{K}_{2}=-\mathrm{V}_{\mathrm{s}} \alpha / \omega_{\mathrm{d}}$, then

$$
\begin{aligned}
V_{c}(t)=-V_{S} e^{-\alpha t}\left(\cos \omega_{d} t+\frac{\alpha}{\omega_{d}} \sin \omega_{d} t\right)+V_{S}=V_{S}\left[1-e^{-\alpha t} \sqrt{1+\frac{\alpha^{2}}{\omega_{d}^{2}}}\left(\frac{1}{\sqrt{1+\frac{\alpha^{2}}{\omega_{d}^{2}}}} \cos \omega_{d} t+\frac{\alpha}{\omega_{d} \sqrt{1+\frac{\alpha^{2}}{\omega_{d}{ }^{2}}}} \sin \omega_{d} t\right)\right. \\
=V_{S}\left[1-\frac{\omega_{0}}{\omega_{d}} e^{-\alpha t} \cos \left(\omega_{d} t-\theta\right)\right], \quad t \geq 0,\left(\theta=\operatorname{arctg} \frac{\alpha}{\omega_{d}}\right)
\end{aligned}
$$

If the exciting source is a causality pulse voltage source $\mathrm{u}_{\mathrm{s}}=\varepsilon(\mathrm{t})-2 \varepsilon(\mathrm{t}-\mathrm{T} / 2)+2 \varepsilon(\mathrm{t}-\mathrm{T})-2 \varepsilon(\mathrm{t}-\mathrm{T}-\mathrm{T} / 2)+2 \varepsilon(\mathrm{t}-2 \mathrm{~T})-2 \varepsilon(\mathrm{t}-2 \mathrm{~T}-\mathrm{T} / 2)+2 \varepsilon(\mathrm{t}-3 \mathrm{~T}) \ldots$ After the first cycle

$$
\mathrm{V}_{\mathrm{c}}(\mathrm{t})=\left\{\begin{array}{l}
\mathrm{V}_{\mathrm{s}}\left[1-\frac{\omega_{0}}{\omega_{\mathrm{d}}} \mathrm{e}^{-\alpha \mathrm{t}} \cos \left(\omega_{\mathrm{d}} \mathrm{t}-\theta\right)\right]-2 \sum_{\mathrm{k}=1}^{\mathrm{k}} \mathrm{V}_{\mathrm{s}}\left[1-\frac{\omega_{0}}{\omega_{\mathrm{d}}} \mathrm{e}^{-\alpha\left[\mathrm{t}-(\mathrm{k}-\mathrm{l}) \mathrm{T}-\frac{\mathrm{T}}{2}\right]} \cos \left(\omega_{\mathrm{d}}\left[\mathrm{t}-(\mathrm{k}-1) \mathrm{T}-\frac{\mathrm{T}}{2}\right]-\theta\right)\right] \\
+2 \sum_{\mathrm{k}=1}^{\mathrm{k}} \mathrm{V}_{\mathrm{s}}\left[1-\frac{\omega_{0}}{\omega_{\mathrm{d}}} \mathrm{e}^{-\alpha(\mathrm{t}-\mathrm{kT})} \cos \left(\omega_{\mathrm{d}}(\mathrm{t}-\mathrm{kT})-\theta\right)\right], \quad \mathrm{kT}<\mathrm{t}<\mathrm{kT}+\frac{\mathrm{T}}{2} ; \\
\mathrm{V}_{\mathrm{s}}\left[1-\frac{\omega_{0}}{\omega_{\mathrm{d}}} \mathrm{e}^{-\alpha \mathrm{t}} \cos \left(\omega_{\mathrm{d}} \mathrm{t}-\theta\right)\right]-2 \sum_{\mathrm{k}=1}^{\mathrm{k}} \mathrm{V}_{\mathrm{s}}\left[1-\frac{\omega_{0}}{\omega_{\mathrm{d}}} \mathrm{e}^{-\alpha\left[\mathrm{t}-(\mathrm{k}-\mathrm{t}) \mathrm{T}-\frac{\mathrm{T}}{2}\right]} \cos \left(\omega_{\mathrm{d}}\left[\mathrm{t}-(\mathrm{k}-1) \mathrm{T}-\frac{\mathrm{T}}{2}\right]-\theta\right)\right] \\
+2 \sum_{\mathrm{k}=1}^{\mathrm{k}} \mathrm{V}_{\mathrm{s}}\left[1-\frac{\omega_{0}}{\omega_{\mathrm{d}}} \mathrm{e}^{-\alpha(\mathrm{t}-\mathrm{kT})} \cos \left(\omega_{\mathrm{d}}(\mathrm{t}-\mathrm{kT})-\theta\right)\right] \\
-2 \mathrm{~V}_{\mathrm{s}}\left[1-\frac{\omega_{0}}{\omega_{\mathrm{d}}} \mathrm{e}^{-\alpha\left(\mathrm{t}-\mathrm{kT}-\frac{\mathrm{T}}{2}\right)} \cos \left(\omega_{\mathrm{d}}\left(\mathrm{t}-\mathrm{kT}-\frac{\mathrm{T}}{2}\right)-\theta\right)\right], \quad \mathrm{kT}+\frac{\mathrm{T}}{2}<\mathrm{t}<(\mathrm{k}+1) \mathrm{T}
\end{array}\right.
$$

\section{EXPERIMENTAL DEVICE AND RESULTS}

The practical circuit frame of the experimental device is shown in Fig. 1. The device is initially analyzed with normal inductor for calibration. Fig. 2 shows the voltage waveform $\mathrm{V}_{\mathrm{c}}(\mathrm{t})-\mathrm{t}$ at $\mathrm{f}_{\mathrm{s}}=40 \mathrm{~Hz}$, where the circuit has constants of $\mathrm{L}=331$ $\mathrm{mH}, \mathrm{C}=220 \mathrm{nF}$ and $\mathrm{R}=400 \Omega$. The circuit attenuation coefficient $\alpha=R /(2 L)=604.2$. Fig. 3 shows the voltage waveform $V_{c}(t)-t$ at $f_{s}=100 \mathrm{~Hz}$, and Fig. 4 shows the voltage waveform $\mathrm{V}_{\mathrm{c}}(\mathrm{t})-\mathrm{t}$ at $\mathrm{f}_{\mathrm{s}}=589 \mathrm{~Hz}$. When the pulse square waveform frequency becomes closer to the $\mathrm{f}_{\mathrm{o}}\left\{=[2 \pi \sqrt{ }(\mathrm{LC})]^{-1}\right\}$, $\mathrm{V}_{\mathrm{c}}(\mathrm{t})$ becomes sinusoid with the $\mathrm{Q}=3.1$ for the situation. Fig. 5 shows the $\mathrm{V}_{c}(\mathrm{t})$ peak value variation during frequency scanning with a steady sinusoid excitation. Since the experimental circuit has maximum $\mathrm{Q}=8.2$, the peak $\mathrm{V}_{\mathrm{c}}(\mathrm{t})$ is limited below $104 \mathrm{~V}$.

The device is then verified with superconducting inductor.
The circuit has the same constants but the different resistance for this case. Fig. 6 shows the $\mathrm{V}_{\mathrm{c}}(\mathrm{t})$ increase against time, where $t=0$ is the experiment starting point with inductor resistance $\mathrm{R}_{\mathrm{L}}=148.5 \Omega$. Fig. 7 shows the resistance decrease against time, where Fig. 8 is the variation of its $Q$ values.

Fig. 9 shows the $\mathrm{V}_{\mathrm{c}}(\mathrm{t})$ with decreased circuit resistance $\mathrm{R}_{\mathrm{L}}=$ $18.48 \Omega$. Fig. 10 is the case for $f_{s}=100 \mathrm{~Hz}$, and Fig. 11 is for $f_{s}$ $=589 \mathrm{~Hz}$. The maximum voltage $\mathrm{V}_{\mathrm{p}}$ can be achieved at the resonant point as shown in Fig. 12 by frequency scanning.

When minimizing the circuit resistance by using HTS technology, the potentially achievable voltage can be significantly increased as shown in Fig. 13, where the circuit has $\mathrm{R}=0.33 \Omega$; and Fig. 14 is its corresponding current. 


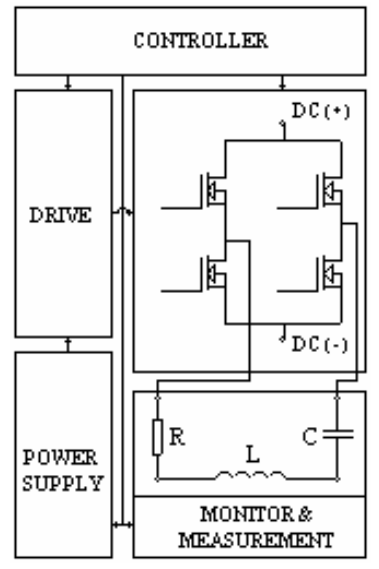

Fig. 1. Principle configuration of a practical experimental device circuit frame.

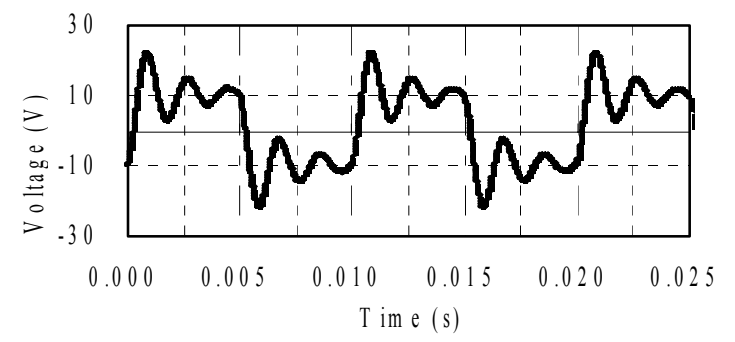

Fig. 2. $V_{c}(t)$ at $f_{s}=40 \mathrm{~Hz}$..

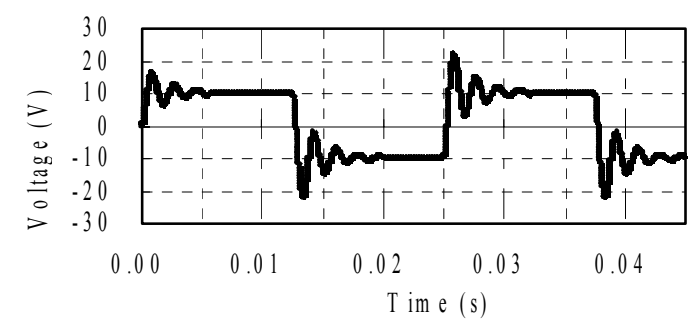

Fig. 3. $\mathrm{V}_{\mathrm{c}}(\mathrm{t})$ at $\mathrm{f}_{\mathrm{s}}=100 \mathrm{~Hz}$.

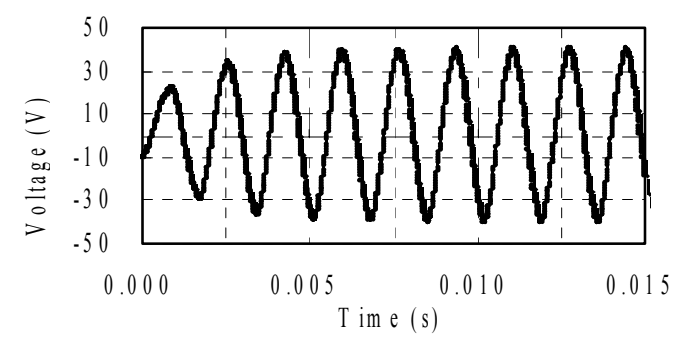

Fig. 4. $\mathrm{V}_{\mathrm{c}}(\mathrm{t})$ at $\mathrm{f}_{\mathrm{s}}=589 \mathrm{~Hz}$.

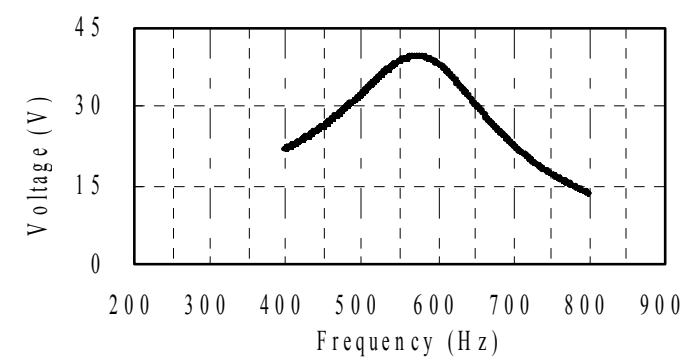

Fig. 5. $V_{c}(t)$ peak values with different $f$ during frequency scanning.

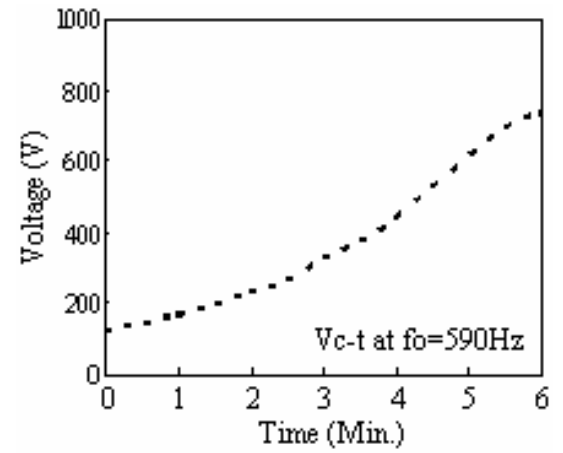

Fig. 6. Measurement results of $V_{c}(t)-t$ at $f_{o}=590 \mathrm{~Hz}$.

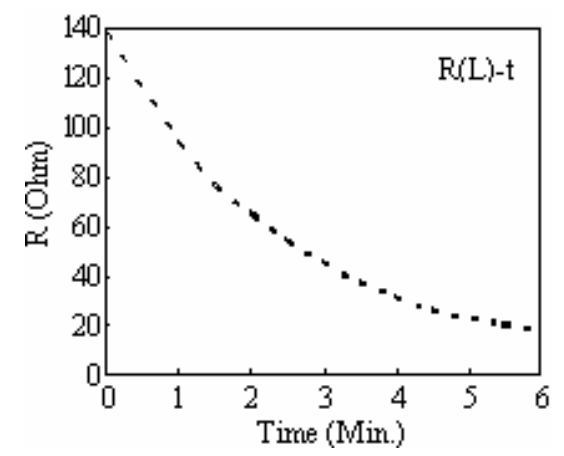

Fig. 7. Measurement results of $R_{L}$ during the test.

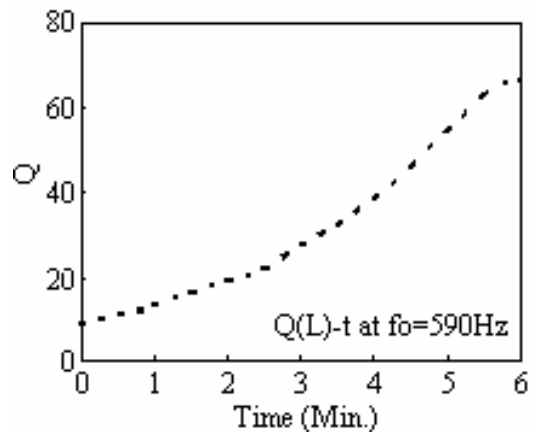

Fig. 8. Measurement results of the variation of $\mathrm{Q}$ values during the test.
Fig. 9. $V_{c}(t)$ at $f_{s}=40 \mathrm{~Hz}$.

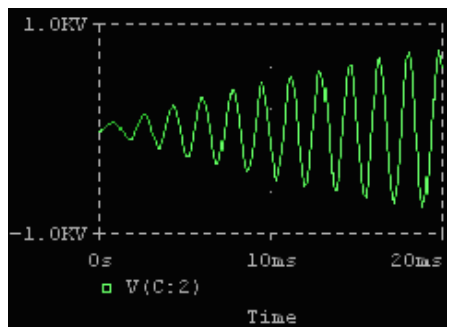

Fig. 11. $\mathrm{V}_{\mathrm{c}}(\mathrm{t})$ at $\mathrm{f}_{\mathrm{s}}=589 \mathrm{~Hz}$.

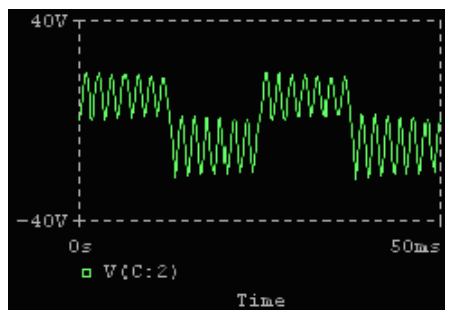

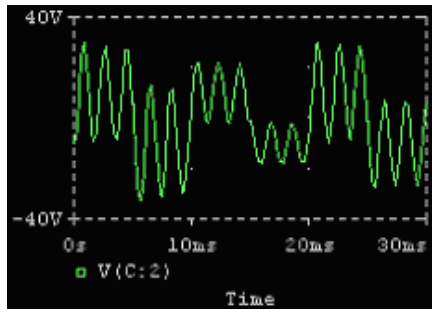

Fig. 10. $V_{c}(t)$ at $f_{s}=100 \mathrm{~Hz}$.

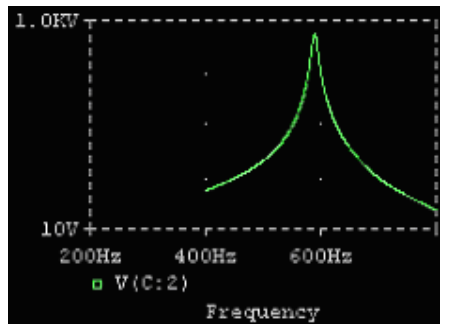

Fig. 12. $V_{p}$ at different $f$. 


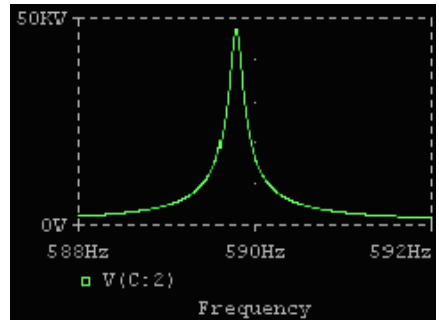

Fig. 13. $\mathrm{V}_{\mathrm{p}}$-f with $\mathrm{R}=0.33 \Omega$.

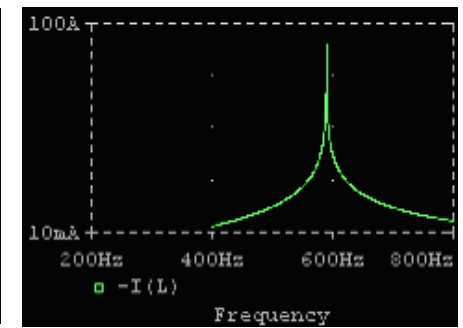

Fig. 14. $\mathrm{I}_{\mathrm{p}}$-f with $\mathrm{R}=0.33 \Omega$.

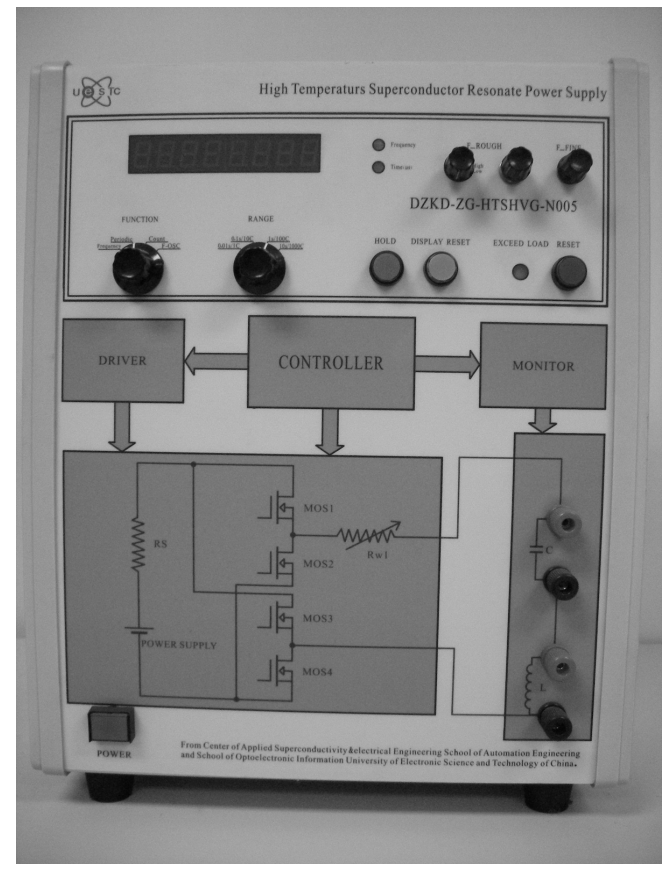

Fig. 15. The practical electronic resonant controller device.

\section{Discussion}

With a HTS, the resonant circuit can be a very high Q circuit, special aspects such as a very high voltage can be built up or a high current can be controlled. With regard to the voltage built up, practically any circuit resistance causes energy dissipation, and for each cycle or reversal of the DC source polarity for example, the corresponding increase in voltage is less than $2 V_{B}$, and the magnitude of the voltage increase gets smaller with each iteration. Any resistance in the circuit will limit the final achievable voltage. To reduce the circuit resistance to near zero leads to an infinite circuit quality factor $\mathrm{Q}$ at resonance. In a series resonant circuit with a power supply $\mathrm{V}_{\mathrm{ps}}=\mathrm{V}_{\mathrm{m}} \sin \omega \mathrm{t}$, the rms current $I_{\max }$ in the circuit at resonance is $I_{\max }=V_{m} /(R \sqrt{2})$, and the voltage across the capacitor $\mathrm{V}_{\mathrm{Cmax}}(\mathrm{rms})$ is $\mathrm{V}_{\mathrm{Cmax}}=\mathrm{X}_{\mathrm{C}}$ $\mathrm{I}_{\max }=\left(\omega_{0} \mathrm{C}\right)^{-1}\left[\mathrm{~V}_{\mathrm{m}} /(\mathrm{R} \sqrt{ } 2)\right]$. By assuming that the circuit resistance $\mathrm{R}$ is zero, the circuit then has infinite $\mathrm{Q}$ at resonant frequency $\omega_{0}=1 / \sqrt{ }(\mathrm{LC}) \mathrm{rad} \mathrm{s}^{-1}$. This leads to an infinite value of $\mathrm{V}_{\mathrm{C}}$ generated and a very large potential current. This device therefore is able to provide controls of both high voltages and high currents. The HTS technology is critical for this method to be practical. The high $\mathrm{Q}$ inductor is able to be realized by using HTS Ag-clad $(\mathrm{Bi}, \mathrm{Pb})_{2} \mathrm{Sr}_{2} \mathrm{Ca}_{2} \mathrm{Cu}_{3} \mathrm{O}_{10+x}$ wires, which have been verified and have potential capability to make the inductor winding [3]-[6]. The HTS inductor virtually has no resistance for a DC current operation; however loss will be generated even at a relative low value and low frequency $\mathrm{AC}$ current application, which however does not affect this application significantly [7]. The HTS wires can be used to achieve the very high $\mathrm{Q}$ inductor to make this method viable; on the other hand the conventional inductor technique can not make this method applicable because of the limited Q value.

\section{CONCLUSION}

A high Q resonant circuit with a power electronic controller has been verified with theoretical and also operational analysis, which forms a base to practically develop this high Q resonant method with HTS technology. This method generates special aspects for applications, such as high voltage built up and high current control, which can be readily achieved by using the newly developed HTS technology.

\section{ACKNOWLEDGMENT}

Thanks are due to A/Prof. C. Grantham, Mr. L.H. Zheng, Ms. H.L. Yan, and Dr. X.P. Gu providing help for this work.

\section{REFERENCES}

[1] J. X. Jin, S. X. Dou, H. K. Liu, and C. Grantham, "High voltage generation with a high $\mathrm{T}_{\mathrm{c}}$ superconducting resonant circuit," IEEE Transactions on Applied Superconductivity, vol. 7, no. 2, 1997, pp. 881884.

[2] J. X. Jin, S. X. Dou, F. Darmann, M. Apperley, T. Beales, "Development of an HTS inductor for an electronic high voltage generator," Physica C, vol. 341-348, no. 1-4, 2000, pp. 1601-1602.

[3] J. X. Jin, C. Grantham, H. K. Liu, and S. X. Dou, " $(\mathrm{Bi}, \mathrm{Pb})_{2} \mathrm{Sr}_{2} \mathrm{Ca}_{2} \mathrm{Cu}_{3} \mathrm{O}_{10+\times}$ Ag-clad high- $\mathrm{T}_{\mathrm{c}}$ superconducting coil and its magnetic field properties," Philosophical Magazine B, vol. 75, no. 6, 1997, pp. 813-826.

[4] J. X. Jin, S. X. Dou, C. Grantham, and H. K. Liu, "Preparation of high $T_{c}$ superconducting coils for consideration of their use in a prototype fault current limiter," IEEE Transactions on Applied Superconductivity, vol. 5, no. 2, 1995, pp. 1051-1054.

[5] Y. C. Guo, J. X. Jin, H. K. Liu, Y. Tanaka, and S. X. Dou, "Long lengths of silver-clad Bi2223 superconducting tapes with high current-carrying capacity," Applied Superconductivity, vol. 5, no. 1-6, 1997, pp. 163-170.

[6] J. X. Jin, and S. X. Dou, "A high temperature superconducting winding and its techniques," Physica C, vol. 341-348, no. 1-4, 2000, pp. 2593-2594.

[7] T. Hardono, C. Cook, and J. X. Jin, "Measurements of ac loss in HTSC wires exposed to an alternating field using calorimetric methods," IEEE Transactions on Applied Superconductivity, vol. 9, no. 2, 1999, pp. 813-816. 